\title{
Discurso econômico e política colonial no Império Luso-Brasileiro (1750-1808) ${ }^{1}$
}

\author{
José Luís Cardoso ${ }^{2}$
}

\section{Alexandre Mendes Cunha ${ }^{3}$}

O artigo reflete sobre a ação política do marquês de Pombal e de Dom Rodrigo de Souza Coutinho, comparando o conjunto de suas orientações no campo econômico e colocando em perspectiva a questão geral do reformismo ilustrado no mundo ibérico. A ambição geral é a discussão de diferentes percursos no plano da história das ideias no século XVIII, mapeando o quadro de influências ao discurso econômico e político dedicado à concepção e execução das reformas, com destaque para a preocupação com o papel das colônias (o Brasil, essencialmente) na dinâmica econômica portuguesa ao longo da segunda metade do século XVIII.

Palavras-chave: Reformismo Ilustrado - Política Colonial - Império Luso-brasileiro

Economic Discourse and Colonial Policy in the Luso-Brazilian Empire (1750-1808)

The article is a reflection on the policies of the Marquis of Pombal and Dom Rodrigo de Sousa Coutinho, comparing their aims in the economic field and putting in perspective the general question of enlightened reformism in the Iberian world. Aiming at a discussion of the different paths in the history of ideas in the $18^{\text {th }}$ century, the article explores the framework of influences on economic and political discourse with regard to the conception and implementation of reforms, stressing the concern with the role of colonies (essentially Brazil) in the Portuguese economy during the second half of the $18^{\text {th }}$ century.

Keywords: Enlightened reformism - Colonial policy - Luso-Brazilian Empire

\footnotetext{
${ }^{1}$ Artigo recebido e aprovado para publicação em janeiro de 2011.

${ }^{2}$ ICS, Universidade de Lisboa.

${ }^{3}$ Cedeplar, Universidade Federal de Minas Gerais. O autor agradece o auxílio financeiro do CNPq e da FAPEMIG para a pesquisa.
} 
Discours économique et politique colonial dans l'empire luso-brésilien (17501808)

Cet article examine l'action politique du Marquis de Pombal et celle de Rodrigo de Sousa Coutinho, afin de mettre en perspective leurs respectives orientations en matière économique, ainsi que la question du réformisme des Lumières dans le monde ibérique. Larticle propose une discussion sur les différents parcours suivis dans l'histoire des idées au XVIIIème siècle. Les auteurs présentent le cadre des références où ces discours économiques et politiques sont nés, et en particulier en ce qui concerne la conception et la mise en oeuvre des réformes coloniales. Celles-ci sont décisives pour mieux comprendre le rôle que le Brésil a joué dans l'économie portugaise de la deuxième moitié du XVIIIe siècle.

Mots-clés: Réformisme des Lumières - Politique coloniale - Empire luso-brésilien

\section{Introdução}

O presente texto busca refletir sobre os períodos em que o marquês de Pombal e Dom Rodrigo de Souza Coutinho estiveram no centro do poder político no Estado português, comparando o conjunto de suas orientações no campo econômico e colocando em perspectiva a questão geral do reformismo ilustrado no mundo ibérico. De maneira mais concreta, e com ambição mais adequada ao escopo e aos limites do presente texto, pode-se dizer que nosso objetivo principal aqui é avançar na resposta a duas perguntas: 1) em que diferem, no que concerne à natureza das formulações econômicas e políticas, Pombal e os governos que $\mathrm{o}$ antecederam?; e 2) em que efetivamente diferem os períodos de Pombal e Dom Rodrigo?

Tendo como ponto de partida, por um lado, as polêmicas acerca do papel desempenhado por Pombal em relação à entrada das Luzes em Portugal e à influência destas na sua ação governativa, e, por outro, o relativo acordo por parte da historiografia em relação à associação entre o ideário ilustrado e as reformas promovidas por Dom Rodrigo de Souza Coutinho no governo português na última década do século XVIII, julgamos que encaminhar respostas a essas duas perguntas permite tanto mapear certos embates historiográficos quanto também, esperamos, oferecer algumas luzes novas acerca da história das ideias no período. 
Interessa aqui, portanto, discutir percursos particulares no plano da história das ideias no século XVIII. Nesse sentido, o desafio fundamental é o de delimitar um quadro de influências ao discurso econômico e político dedicado à concepção e execução das reformas econômicas e políticas, com destaque para a preocupação com o papel das colônias (o Brasil, essencialmente) na dinâmica econômica portuguesa ao longo da segunda metade do século XVIII.

Essa articulação entre a ação reformista dentro do pensamento ilustrado e o tema das colônias é sem dúvida fundamental para compreender casos como o das monarquias ibéricas no período. Gabriel Paquette, em dois livros recentes, contribui incisivamente para a reflexão acerca do reformismo ilustrado e de sua utilização como conceito organizador das ações governativas na Europa do Sul (os países ibéricos, fundamentalmente) e seus impérios atlânticos na segunda metade do século XVIII e primeiras décadas do XIX. ${ }^{4}$ Para esse autor, a ideia de reformismo ilustrado constitui elemento fundamental para abordar esse momento da história desses Estados europeus. Os desafios desses Estados para manter seus impérios coloniais e a partir deles ativar amplos circuitos econômicos configuram em boa medida elemento central das ações reformistas no período, sendo o ritmo, a direção e a amplitude das reformas metropolitanas influenciados em grande medida pelos assuntos coloniais. ${ }^{5}$ A leitura do reformismo ilustrado como elemento importante para a compreensão do contexto português das últimas décadas do século XVIII, com especial destaque para as transformações no discurso econômico, também vem sendo alvo de alguns de nossos trabalhos nos últimos anos. ${ }^{6}$

\footnotetext{
${ }^{4}$ Gabriel B. Paquette (org.), Enlightened reform in Southern Europe and its atlantic colonies, c. 17501830, Farnham, Ashgate, 2009, e Gabriel B. Paquette, Enlightenment, governance and reform in Spain and its empire, 1759-1808, Basingstoke/Nova York, Palgrave Macmillan, 2008.

${ }^{5}$ Gabriel B. Paquette, Enlightened reform in Southern Europe and its atlantic colonies, c. 1750-1830, p. 2-3. ${ }^{6}$ Acerca dessa questão, veja especialmente: José Luís Cardoso, "Nas malhas do império: a economia política e a política colonial de D. Rodrigo de Sousa Coutinho". In: José Luís Cardoso (org.), A economia política e os dilemas do império luso-brasileiro (1790-1822), Lisboa, Comissão Nacional para as Comemorações dos Descobrimentos Portugueses, 2001, e Alexandre Mendes Cunha, "Police science and cameralism in Portuguese enlightened reformism: economic ideas and the administration of the State during the second half of the 18th century", e-Journal of Portuguese History, v. 8, p. 3, 2010. Cite-se aqui, também, outro de nossos trabalhos, a ser publicado no próximo ano, que aprofunda alguns pontos expressos no presente texto, em particular no que diz respeito aos lugares do cameralismo e do discurso da economia política nas transformações do pensamento econômico luso-brasileiro no período: José Luís Cardoso \& Alexandre Mendes Cunha, "Enlightened reforms
} 
O conceito de reformismo ilustrado é sem dúvida útil e importante, mas não são poucos os desafios envolvidos nessa perspectiva de análise, a começar pelo fato de que se ajuntam aí a ação reformista, por definição dedicada a "reaparelhar" estruturas próprias do Antigo Regime de modo a continuarem existindo, e o Iluminismo, com suas indissociáveis potencialidades transformadoras do real. Mas em boa medida é exatamente esse mesmo o plano de contradições que se dramatiza em contextos distintos a partir de meados do século XVIII e dá corpo, por exemplo, à bem estabelecida categoria de despotismo esclarecido. Não obstante, como Nuno Monteiro vai argumentar em texto recente incluído na coletânea organizada por Paquette, essas tentativas de recompor as bases da força e centralidade da ação de governo podem ser recuadas a pelo menos o século XVII, tendo como modelos Colbert na França ou Olivares e os arbitristas na Espanha. ${ }^{7}$ Para Monteiro, são exatamente esses os modelos e a tradição aos quais apela Pombal na sua trajetória de centralização administrativa e de transformação das instituições portuguesas a partir de 1755.

Pois bem, as perguntas enunciadas anteriormente ganham particular sentido dentro desse registro. Ou seja, é possível afirmar que as reformas empreendidas por Dom Rodrigo de Souza Coutinho guiaram-se por matrizes ilustradas, enquanto a ação de Pombal constitui-se mais propriamente em um prolongamento de linhas de força e modelos já configurados no século XVII?

$\mathrm{O}$ argumento geral do texto é de que, independentemente de uma série de mudanças que já há muito se encontram bem exploradas na historiografia, há importantes traços de continuidade entre os governos de Pombal e de Dom Rodrigo, respondendo ambos, ainda que com especificidades bem marcadas, ao rótulo geral de reformismo ilustrado, e, da mesma forma, há clara distinção entre Pombal e os governos que o precederam no que concerne à forma e ao conteúdo de sua ação reformadora. Nesse sentido, a leitura do conteúdo mercantilista das iniciativas pombalinas, por exemplo, não é conflituosa com essa atribuição de caráter ilustrado a suas reformas, uma vez que o próprio mercantilismo é um termo volátil que dá conta de uma base de conhecimentos que foi se recompondo

and economic discourse in the Portuguese-Brazilian empire (1750-1808)", History of Political Economy, 2012 (no prelo).

${ }^{7}$ Nuno Gonçalo Monteiro, “Pombal's government: between seventh-century valido and enlightened models". In: Gabriel B. Paquette (org.), Enlightened reform in Southern Europe and its atlantic colonies, c. 1750-1830, Farnham, Ashgate, 2009. 
ao longo de três séculos e que àquele momento incorporava uma série de autores influenciados diretamente pelas ideias ilustradas, como bem é o caso de Johann Heinrich Gottlob von Justi e de outros nomes do cameralismo tardio no mundo germânico. É possível ler na ação reformadora de Pombal, em particular em relação a algumas das instituições centrais por ele criadas, às quais se fará menção na parte seguinte deste artigo, uma perspectiva nova de ação, informada sem dúvida por uma linhagem de ideias diferente, que, ainda que articulada aos preceitos mercantilistas, abria-se decisiva e irreversivelmente a novas perspectivas. Já na parte do texto dedicada, por sua vez, à ação reformadora em Dom Rodrigo de Souza Coutinho, será possível perceber como exatamente essas novas perspectivas, abertas já no espaço da ação governativa pombalina, serão por fim decisivas para a orientação das reformas econômicas, com destaque claro à questão colonial e ao tema do império luso-brasileiro.

É importante ter em conta que durante esse período o estatuto das colônias dentro do quadro geral dos impérios europeus está a sofrer alterações substanciais, alterações essas que culminariam, por fim, em processos diversos de autonomia política. Tendo-se em conta os argumentos que normalmente são apresentados pela literatura econômica mercantilista que se ocupou das questões coloniais, seria o papel das colônias funcionar no sentido de garantir o abastecimento de matérias-primas e bens de consumo, quer para uso direto nas metrópoles, quer para fins de reexportação. Para além disso, pretendia-se também que estas funcionassem como um mercado protegido para a colocação dos produtos fabricados nas metrópoles.

É exatamente essa perspectiva de análise, que dá corpo ao que se entende por "pacto colonial", que estava em vias de mudança à altura da segunda metade do século XVIII, por conta dos desafios apresentados por um novo tipo de discurso econômico e político de cariz ilustrado. Essa perspectiva ilustrada do discurso econômico pode ser encontrada em diferentes matrizes, que na Europa continental àquele momento se difundiam e por vezes se combinavam e recombinavam.

É possível ver nas doutrinas do mercantilismo tardio, da aritmética política ou no cameralismo germânico - matrizes de ideias distintas, mas coincidência no posicionamento do Estado em relação à ação econômica - um quadro de ideias que direta ou indiretamente inspiraram as políticas implementadas pela administração colonial portuguesa durante o terceiro quartel do século XVIII. 
Há de se ter em conta, todavia, que essa perspectiva é parte desse conjunto de recombinações e, como tal, foi também em parte transformada pela compreensão de certos autores influenciados por Adam Smith, que em si é o principal responsável por conciliar em seu tempo os aspectos da compreensão da realidade econômica com os objetivos de intervenção pública. Smith, cujo sistema de economia política também incluiria uma nova perspectiva de análise em relação à natureza do comércio colonial e sua necessidade de transformação, será sem dúvida influência importante ao reformismo português no final do século, sendo isso também um dos temas que serão apresentados adiante, especificamente na seção dedicada a Dom Rodrigo.

\section{O absolutismo ilustrado e Pombal}

A leitura da trajetória governativa de certo conjunto de Estados europeus na segunda metade do século XVIII como uma combinação do esforço para robustecer e centralizar o poder dos soberanos com a abertura a um novo horizonte de ideias, inspirando certa perspectiva reformista, é a base do que fica conhecido como despotismo esclarecido ou absolutismo ilustrado e que está associado à atuação de monarcas diversos, como Catarina II da Rússia, Carlos III da Espanha, Frederico II da Prússia, Maria Tereza e José II da Áustria, entre outros.

O nome de Pombal é costumeiramente incluído nesse tipo de listas, muito embora a dificuldade elementar a isso seja justamente o fato de que não se tratava do monarca e sequer de um efetivo primeiro-ministro, posto que o cargo não existia como tal em Portugal. Essa é uma das linhas exploradas com propriedade por Monteiro no sentido de problematizar a percepção de Pombal dentro do quadro do absolutismo ou reformismo ilustrado, apresentando o ministro como inserido em uma tradição que efetivamente remonta ao século XVII. Mas é possível problematizar esse quadro e tentar situar melhor a figura de Pombal como o ministro que era, mas ao mesmo tempo como a personalidade diretamente associável ao absolutismo ilustrado dentro da monarquia portuguesa. ${ }^{8}$

O primeiro ponto a ser referido é que de fato a percepção do momento do absolutismo ilustrado antes como continuidade do que como uma nova orien-

\footnotetext{
${ }^{8}$ Nuno Gonçalo Monteiro, "Pombal's government: between seventh-century valido and enlightened models". In: Gabriel B. Paquette (org.), Enlightened reform in Southern Europe and its atlantic colonies, c. 1750-1830, Farnham, Ashgate, 2009.
} 
tação insere-se em amplo debate historiográfico. Charles Ingrao a esse respeito escreveu que poucas controvérsias têm durado tanto e ao mesmo tempo chegado a tão poucos pontos definitivos quanto o debate sobre o absolutismo ilustrado. No entanto, adverte que o caminho para buscar tanto a intenção quanto a extensão do absolutismo ilustrado depende necessariamente da capacidade de reconhecer os vieses culturais presentes nos estudos de cada caso nacional isoladamente e da habilidade de transcendê-los no sentido de identificar elementos próprios de um quadro geral. ${ }^{9}$ A abordagem é próxima à de Franz Szabo, que reforça o fato de que diversos historiadores tenderam a perceber o despotismo esclarecido apenas como um instrumento de adaptação, e não de transformação, de estruturas sociais tradicionais; ${ }^{10}$ ou ainda, na frase sarcástica de Perry Anderson, de que se trata mais propriamente de uma "nova carapaça política de uma nobreza atemorizada". ${ }^{11}$ Szabo aponta, entretanto, que essa linha de interpretação, que insiste nos aspectos repressivos dessa modalidade do absolutismo como uma incongruência com o que seria suposto esperar de um espaço político inspirado pelas Luzes, e que como tal termina por fazer uma leitura de que o resultado geral tem mais efeitos de atraso do que de desenvolvimento, não faz jus a todos os casos do absolutismo ilustrado e em especial não combinaria com a experiência da Áustria. Em sua análise, haveria no Império Habsburgo um conjunto de particularidades que permitiram, a partir de um momento de crise na década de 1740, a construção de um tipo de centralização capaz de obliterar particularismos de corpos intermediários da sociedade tradicional e encaminhar a formação de um tipo de corpo burocrático de modo a sustentar a ação administrativa, sendo esse movimento passível de compreensão somente se ponderado em função do quadro geral da ilustração. Para esse autor, não era possível para a Áustria desenvolver um projeto de absolutismo nos moldes franceses do século XVII, mas, ao mesmo tempo, os "novos ventos" que então sopravam da ilustração

\footnotetext{
${ }^{9}$ Charles Ingrao, "The problem of "enlightened absolutism" and the German States", Journal of Modern History, v. 58, supl., 1986, p. 161.

${ }^{10}$ Franz Szabo, Kaunitz and enlightened absolutism, 1753-1780, Cambridge, Cambridge University Press, 1994, p. 6.

${ }^{11}$ Perry Anderson, Linhagens do Estado absolutista, Porto, Afrontamento, 1984, p. 17.
} 
europeia abriam novas possibilidades que foram exploradas em termos de uma efetivamente nova perspectiva política. ${ }^{12}$

O que de fato se pode depreender desse contexto de transformações na Áustria é que, ao longo dos governos de Maria Teresa e José II, foi construído, com base em uma série de reformas, um quadro institucional capaz de efetivar a centralização política, sendo as peças fundamentais que suportariam esse desenho a formação de uma burocracia especializada e que implica novos padrões de ensino, a posição do governante como fonte direta da produção de leis (a figura do reilegislador a que faremos referência adiante) e o favorecimento à concentração de poderes nas mãos de ministros que estariam à frente da criação e condução de instituições destinadas a romper com os entraves à centralização e ao melhor desempenho das finanças públicas oriundos dos particularismos próprios da estrutura tradicional daquela sociedade. Os dois nomes centrais desse processo foram o de Friedrich Wilhelm von Haugwitz e de Wenzel Anton Kaunitz-Rietberg. Haugwitz foi o criador do Directorium in publicis et cameralibus em 1749, instância epítome desse processo de centralização de inspiração cameralista, reunindo funções e atribuições de outras instâncias abrangendo fiscalidade, segurança pública, educação, mineração, comércio, entre outros mais. O organismo perderia parte de suas funções e seria reestruturado com novo nome em 1761; já nesse momento, entretanto, ganha centralidade outro organismo e outro ministro. Kaunitz é o idealizador da proposta de criação de um conselho consultivo permanente, o Conselho de Estado (Staatsrat), com atribuição de analisar, debater e recomendar ou rejeitar as reformas pensadas. Instalado efetivamente em 1761, com confessada inspiração ilustrada por parte de seu criador, o organismo teve a partir de então papel central e preponderante nos rumos do governo, em campos decisivos e distintos como a reorganização das forças de guerra ou a subordinação da Igreja ao Estado.

A posição de Pombal pode ser proveitosamente compreendida tendo esse conjunto de questões em perspectiva. Se o seu modelo inspirador com o qual quis que seu legado se identificasse era de fato o do cardeal Richelieu, primeiroministro de Luís XIII entre 1628 e 1642 e grande artífice do absolutismo na França, ao mesmo tempo o contexto austríaco, que conheceu bem e com o qual

${ }^{12}$ Franz Szabo, Kaunitz and enlightened absolutism, 1753-1780, Cambridge, Cambridge University Press, 1994, p. 74. 
várias articulações podemos estabelecer com o exemplo português, sem dúvida fez parte de seus modelos mentais. Richelieu serviu como personagem inspirador a Pombal como também serviria a Kaunitz na Áustria; todavia, o exemplo prático da conjuntura vienense àquele tempo ofereceria a Pombal respostas a desafios no campo da estruturação das finanças, da posição do Estado em relação à Igreja, entre outros, que seriam mais próximos aos enfrentados por Portugal e que sem dúvida inspiraram o modelo de ação pombalino. Vale lembrar nesse sentido que, tal como na Áustria, foi uma crise, mas com dramaticidade redobrada, que deu oportunidade à condução do processo de centralização do poder em Portugal. O terremoto de Lisboa em 1755 abre essa perspectiva que Pombal, contando com a confiança irrestrita do monarca, soube utilizar para se projetar a uma posição central no poder. ${ }^{13}$

Antes de assumir a pasta dos Negócios Estrangeiros e da Guerra em 1750, quando da ascensão ao trono de Dom José I, e anos mais tarde, em 1776, estampando já a efetiva ampliação de seus poderes dentro do governo ao migrar para o comando da Secretaria de Negócios do Reino, Pombal serviu como embaixador português em Londres (1739-1743) e em Viena (1745-1749), sendo essas experiências diplomáticas sobremaneira relevantes para sua formação intelectual. Em Londres, aproximou-se do círculo da Royal Society e construiu uma biblioteca pessoal, que incluía os mais relevantes livros representativos da literatura mercantilista, como os de Joshua Child, Charles Davenant, Charles King, Thomas Mun e William Petty.

Em Viena, por sua vez, Pombal circulou entre a alta aristocracia e também a alta administração do império austríaco, sendo suas conexões cruciais para o desenvolvimento, por exemplo, de novas ideias sobre questões relacionadas com a reforma da educação e a inovação pedagógica, que viria a dar forma mais tarde a algumas das realizações mais notáveis de sua carreira política. A criação do Real Colégio dos Nobres, em 1761, tem, por exemplo, evidente proximidade com o Theresianum, criado em Viena em 1746, com o fito de educar os jovens membros

\footnotetext{
${ }^{13}$ Em relação à leitura do terremoto como uma oportunidade para a mudança no quadro geral da administração portuguesa no período, com particular impacto na organização das finanças, veja: José Manuel Subtil, O terramoto politico (1755-1759). Memória e poder, Lisboa, UAL, 2007, e Alexandre Mendes Cunha, "Polizei and the system of public finance: tracing the impact of cameralism in 18th century Portugal”. In: Heinz Kurz, Keith Tribe \& Tamotsu Nishizawa (orgs.), The dissemination of economic ideas. Cheltenham, Edward Elgar, 2011.
} 
da aristocracia para as funções de Estado, preparando-os com sólidos conhecimentos científicos e de línguas modernas. Da mesma forma, pode-se argumentar que sua estada em Viena o tenha ajudado também na percepção de novos problemas gerais relativos à gestão política e às ciências do Estado, incluindo aí a percepção mesmo que mais prática do que teórica de princípios cameralistas aplicados à condução da administração do Estado.

\section{Pombal, mercantilismo e as reformas da política colonial}

A ação governativa de Pombal deu destaque aos temas gerais da organização do império e da eficiência das práticas mercantilistas como alavancas para a retomada de posição de Portugal no cenário de uma Europa que assistia à então primazia e ao vívido crescimento da França e, especialmente, da Inglaterra, esta última conhecida em detalhe por Pombal e alvo maior de suas preocupações. Sua compreensão dos entraves ao crescimento do poderio e da riqueza de Portugal orientava suas ações. Partindo da avaliação da enorme dependência de sua nação ante a Inglaterra, dependência essa que se fez crescente desde o apoio firmado no tratado cromwelliano de 1654 à independência ante a Espanha, Pombal tenderia a ver o quadro geral como o de um crescente dreno das riquezas, especialmente do ouro e dos diamantes que vinham da capitania de Minas, em favorecimento da economia inglesa. Tendo isso por pressuposto, é possível ler as ações do ministro como pesadamente orientadas no sentido de imprimir um novo curso a essa situação econômica, política e administrativa. ${ }^{14}$

A compreensão acurada do complexo comercial do mundo luso, especificamente do intercâmbio anglo-português e dos distintos papéis da metrópole e das colônias nesse jogo que fazia com que a balança comercial favorecesse a Inglaterra nos termos das trocas regidas pelo tratado de Metheuen de 1703, foi determinante para uma ação política realmente efetiva para os interesses de Portugal. Mesmo sem afastar sua atenção do açúcar e do tabaco da América portuguesa (o que se reflete na criação das Mesas de Inspeção, ainda em 1751), as minas de ouro foram uma preocupação central e constante à política pombalina, sendo uma

${ }^{14}$ Kenneth Maxwell, $A$ devassa da devassa: a inconfidencia mineira. Brasil-Portugal-1750-1808, Rio de Janeiro, Paz e Terra, 1978, Capítulos 1 e 2, e Kenneth Maxwell, Marquês de Pombal: paradoxo do Iluminismo, Rio de Janeiro, Paz e Terra, 1996, Capítulo 3. 
de suas primeiras medidas a reforma nos métodos de fiscalização da produção aurífera.

Em síntese, a política mercantil e imperial tocada por Pombal à frente do ministério refletiria logo de saída uma preocupação com a defesa dos produtos básicos do sistema comercial luso-brasileiro (açúcar, tabaco e ouro) em meio a disposições legais específicas para a proteção dos interesses comerciais estabelecidos pelos nacionais e dando corpo a uma vigorosa racionalização dos mecanismos de arrecadação de tributos, essencialmente do quinto real. Esse desenho na condução da política e da economia em Portugal teria como uma de suas mais importantes facetas o desenvolvimento da legislação econômica e a racionalização da estrutura empresarial de forma a favorecer os interesses dos grandes comerciantes portugueses de então; o que se cristalizaria com a criação das companhias monopolistas de comércio, marcando nesse entremeio o espaço da progressiva afirmação social dos homens de negócio naquela sociedade.

Ante essa enumeração da tríade "açúcar, tabaco e ouro", há espaço aqui para lembrar que, sem prejuízo de outras das rupturas que até aqui vêm sendo demarcadas, existe de fato uma linha de continuidade entre esse momento pombalino e o que o precede, exatamente no que diz respeito à centralidade que o Brasil passa a ocupar dentro da dinâmica econômica do império. $O$ último elemento da tríade, o ouro de Minas Gerais, explorado em intensidade crescente a partir dos primeiros anos do século XVIII, vai constituir peça primordial do fausto do reinado de Dom João $\mathrm{V}$ e de um tipo de caminho de centralização administrativa e de organização do comércio colonial do qual fazem parte a criação das Secretarias de Estado em 1736 ou o próprio regime de frotas em 1720, que constitui elemento de continuidade com o processo encampado e aprofundado por Pombal. As ações implementadas na política econômica no período pombalino estão nesse particular, ainda, de fato presas em vários de seus aspectos distintivos a dogmas do pensamento mercantilista. ${ }^{15}$ Não obstante, o que precisa ser apreendido aqui é que o próprio mercantilismo é um espaço de recombinações e entrecruzamento de influências nessa segunda metade do século XVIII, e são essas recombinações que começam a haver no período pombalino e inspiram um ambiente de reformas que estamos aqui a perseguir.

${ }^{15}$ Cf. Franciso José Calazans Falcon, A época pombalina (política económica e monarquia ilustrada), São Paulo, Ática, 1982. 
O reforço da centralidade do Estado em Portugal durante a segunda metade do século XVIII se estabelece com base em um processo de especificação progressiva de funções e atribuições que seriam exclusividade desse poder central. Isso levou, por exemplo, a um aumento do controle do Estado sobre o sistema que rege a atribuição de mercês e privilégios, que era uma característica herdada da estrutura social e política do Antigo Regime. A reforma do sistema de finanças públicas português foi outro exemplo representativo do processo de centralização, uma vez que foi conseguida por meio da assunção pelo Estado de uma série de tarefas fiscais e funções anteriormente exercidas por um grupo disperso de indivíduos, que foram então recompensados com favores reais. O terremoto de Lisboa em 1755, que entre muito mais provocou a ruína financeira e a desgraça de vários desses indivíduos titulares de direitos fazendários, impactou a caótica organização fiscal existente e representou uma excelente oportunidade para a substituição desses interesses dispersos e a racionalização do funcionamento do sistema de finanças públicas. O marco efetivo desse novo ordenamento se dá com a criação do Erário Régio em 1761.

O Erário Régio foi responsável por substituir a estrutura prevalecente de administração da cobrança de impostos e trouxe consigo novo ordenamento e racionalidade ao sistema de administração financeira. Peça primordial nessa reestruturação foi a generalização de técnicas de escrituração contábil com base nas partidas dobradas. A preocupação com o acompanhamento do sistema de financiamento do Estado deu lugar, também, a um controle rigoroso das contas públicas, com a coleta precisa de informações sobre todas as instâncias e departamentos do Erário Régio. O incentivo central e dramático para esses procedimentos inovadores na administração pública foi sem dúvida dado pela situação caótica em que se encontravam os registros públicos após o terremoto de Lisboa de 1755, mas é também clara a percepção que logo se difunde de que não se tratava de recuperar informações e reorganizar os registros, mas de efetivamente transcender o modelo vigente.

Ainda em relação ao processo de centralização política e tentando já dar mais destaque à questão colonial, é possível afirmar que desde o começo da governação pombalina distingue-se uma preocupação clara com o fortalecimento e o controle nacional das riquezas oriundas do comércio ultramarino, o que implica 
a criação de novas instituições, bem como a definição de estratégias específicas para a política colonial.

No que concerne a essas transformações no campo da política colonial no período pombalino, é importante começar por uma consideração sobre o fato em si de que Pombal percebe a necessidade premente de robustecer as bases do pacto colonial, mas também de como isso se associava naquele momento à criação de um tipo de "novo modelo de império", como chamou Jeremy Adelman em sua perspicaz análise das transformações no império colonial das monarquias ibéricas no período. Para esse autor, é esclarecedora a análise em paralelo de Pombal e José Galvéz, visitador general da Nova Espanha entre 1765 e 1771 e ministro das índias de 1776 até sua morte em 1787, que vem a ser o grande artífice do esforço de recentralização do império espanhol. Para Adelman, essa busca, que se materializaria em ambas as monarquias ibéricas, começando antes em Portugal, de um novo modelo de organização econômica do império ganhava forma em um conjunto de reformas que se destinavam a criar um novo pacto com e dentro das Américas. ${ }^{16}$

Em articulação direta do tema da organização das finanças com a questão da busca desse novo modelo de política colonial, é possível insistir aqui que a reestruturação das finanças públicas para o conjunto do império constituiu um dos aspectos mais decisivos das transformações institucionais operadas por Pombal no Estado português, cumprindo a partir de então função estratégica na tentativa de renovar e reavivar o pacto colonial.

A criação do Erário Régio, e com ele de toda uma rede de Juntas da Real Fazenda no reino e nas colônias, estabelece um novo padrão de administração das finanças no império. Centralizado, baseado em modernos princípios de

\footnotetext{
${ }^{16}$ Nos termos do próprio Adelman: "In both empires, therefore, reform was about crating a new pact with, and within, the Americas - in effect to make them 'real' colonies of late mercantilist empires. In a fundamental respect Pombal and Gálvez were proposing to put the tow empires on sounder, if not more perfect, mercantilist foundations. The old conquest model, associated with the quest for gold, silver, and preciosities, was sterile, no stimulating. It had become an end in itself. The task for reformers was not simply to bury the old obsession with the flow of precious metals to private and public coffers, but to transform imperial trade so that bullion could flow more healthily through the body's arteries. In this fashion, Spain and Portugal need not repudiate the past but simply transcend it. Doing so required taking what the conquered and placing these possessions at the service of a different model of wealth and greatness founded on commercial activity" (Jeremy Adelman, Sovereignty and revolution in the Iberian Atlantic, Princeton, Princeton University Press, 2006).
} 
escrituração contábil, permitindo pela primeira vez uma percepção efetiva do quadro geral das finanças do Estado e do lugar ocupado nesse panorama financeiro pelo reino e pelas áreas coloniais, para além de organizado em contadorias que misturavam e articulavam estrategicamente áreas distintas do império, esse novo modelo de administração das finanças reflete com clareza essa busca de um novo modelo para o império.

Um exemplo interessante é oferecido pelas diretrizes estabelecidas para a contabilidade da Junta da Real Fazenda de Minas Gerais, especificando a série de livros que deveriam ser criados e as regras estritas que deveriam ser observadas após a chegada do novo funcionário provido para a posição de escrivão em 1772. Além disso, as orientações também previam a necessidade de uma revisão cuidadosa de todos os registros anteriores compilados desde a criação do Erário Régio em 1761, a fim de organizar eficazmente a administração financeira da colônia. ${ }^{17}$

A organização das finanças faz par direto com a preocupação com a dinamização do comércio dentro do processo de sistematização das políticas econômicas em Portugal empreendido por Pombal, e nesse particular uma instituição criada em 1755 desempenha papel central: a Junta de Comércio. A principal atividade econômica da Junta de Comércio, por sua vez, acaba por ser efetivamente a renovação e a intensificação do comércio colonial. Isso fica particularmente evidente de 1760 em diante, quando se torna patente a retração na produção de ouro em Minas Gerais, diminuindo assim, progressivamente, a receita do quinto, assim como a receita de outros produtos coloniais para reexportação. Essa retração teve um impacto direto e óbvio sobre o desempenho da balança de comércio portuguesa.

A efetivação do pacto colonial não se deu, obviamente, como um tipo de política que naturalmente foi logrando resultados de transformação ${ }^{18}$ Houve de fato um apelo para o reforço e a capacitação dos territórios coloniais, e diferentes estratégias foram implementadas desde início, como a criação das Mesas de Inspeção, destinadas a assegurar tanto a regularidade quanto a qualidade nos embarques de produtos coloniais, sobretudo ao tabaco e ao açúcar. No entanto,

\footnotetext{
${ }^{17}$ Arquivo Histórico do Tribunal de Contas, Fundo Erário Régio, Livro 4.072, p. 105-115.

${ }^{18}$ Cf. Franciso José Calazans Falcon, A época pombalina (política económica e monarquia ilustrada), São Paulo, Ática, 1982.
} 
o ponto focal da política econômica tendeu a ser mesmo o incentivo para a produção colonial, baseado na introdução de novos produtos e na preocupação com o controle do contrabando. Este último aspecto pode ser entendido como um requisito fundamental para o desenvolvimento de uma estratégia monopolista de distribuição de recursos. O principal instrumento utilizado para realizar esse duplo objetivo de controlar o contrabando e estimular a produção foi, por sua vez, a criação de companhias de comércio.

As companhias de comércio, criadas para Grão-Pará em 1755 e para Pernambuco e Paraíba em 1759, tiveram um sucesso notável, especialmente a primeira delas. Na verdade, tão bem-sucedidos foram os empreendimentos que estes se tornaram alvo de protestos e denúncias graves de negociantes tanto portugueses como estrangeiros, por não poderem prosseguir com suas atividades comerciais em áreas protegidas. Por um lado, as companhias de comércio trouxeram uma redução da liberdade dos agentes econômicos, mas por outro serviram também como um poderoso instrumento para o reforço dos interesses nacionais portugueses, como ficou evidente no aumento da atividade da Junta de Comércio. Mesmo com os diferentes níveis de descontentamento interno e desaprovação que experimentaram, as companhias de comércio constituíram-se em um dos aspectos fundamentais para a execução do monopólio colonial no mundo português.

Companhias de comércio não foram criadas, todavia, para todos os territórios coloniais. Um alegado plano desenvolvido pelo Estado português para a criação de mais duas novas companhias (para a Bahia e o Rio de Janeiro) foi um dos alvos de críticas no Memorials of the British consul and factor at Lisbon, um panfleto impresso em Londres em 1766. A resposta oficial portuguesa às queixas por parte dos comerciantes britânicos esclareceu que as alegadas companhias de comércio a serem criadas para a Bahia e o Rio de Janeiro não o seriam porque o comércio dessas regiões já havia florescido e já se constituía em uma fonte de felicidade pública. Foi ainda explicado que essas companhias foram criadas somente para as regiões onde o comércio ainda não havia se desenvolvido ou então nas quais a atividade se encontrava completamente destruída. ${ }^{19}$

19 Cf. Sebastião José de Carvalho e Mello, Cartas e outras obras selectas do marquês de Pombal, Lisboa, Typographia D. Marques Leão, 1823, e Franciso José Calazans Falcon, "O império lusobrasileiro e a questão da dependência inglesa - um estudo de caso: a política mercantilista durante a época pombalina, e a sombra do Tratado de Methuen", Nova Economia, v. 15, n. 2, 2005, p. 26. 
Além da criação de companhias de comércio, a política colonial durante esse período foi concebida para atingir um objetivo principal: a exclusão de estrangeiros, bem como de seus agentes, e para exercer o comércio direto com as colônias portuguesas. Com esse propósito em mente, a flexibilidade passava a ser uma ferramenta importante na regulação do comércio colonial, uma vez que servia para estimular as regiões menos prósperas. Um bom exemplo desse objetivo específico foi o decreto de 10 de junho de 1755 , que removeu os impedimentos existentes no sistema corrente em relação ao comércio com Moçambique, permitindo que todos os habitantes de Goa e das mais distantes partes portuguesas na Ásia pudessem comercializar livremente.

A preocupação da coroa portuguesa com a manutenção e o aumento de sua receita fiscal foi a todo tempo, no entanto, o princípio mais permanente na orientação de suas decisões políticas. Em consonância com isso, algumas das estratégias utilizadas foram a concessão a particulares de monopólios sobre o comércio de alguns produtos coloniais, bem como a cessão dos direitos de cobrança do imposto sobre alguns produtos coloniais (o tabaco é um exemplo bem conhecido). Não obstante, é importante ter em mente que essas medidas não devem ser interpretadas como fatores de maior dispersão para o sistema de arrecadação tributária, mas, sim, como um expediente prático para o financiamento de curto prazo das despesas públicas.

É possível afirmar deste ponto que a política econômica promovida pelo marquês de Pombal não se caracterizou como uma mera extensão do mercantilismo do século XVII no que diz respeito a suas orientações doutrinárias e políticas. Embora essa postura mercantilista não tenha sido efetivamente contestada, a reforma política e as mudanças econômicas que ocorreram em Portugal e no Brasil durante a segunda metade do século XVIII revelaram que a visão mercantilista vigente foi combinada com projetos específicos da ação ilustrada do governo no período, o que apelava para uma relação diferente entre o legislador e seus súditos. A principal diferença dessa nova relação, baseada no princípio do interesse mútuo, era que os direitos exigidos dos indivíduos deviam pautar-se por um senso de responsabilidade pública e de serviço ao bem comum, e não ser apenas uma simples questão de obediência.

Uma questão adicional que, por fim, nos ajuda a compreender o processo envolvido na formação de um novo discurso econômico e político em Portu- 
gal ao longo desse período é a influência da filosofia do jusnaturalismo, ou, em outros termos, a importância do Direito Natural como justificativa para a o sistema político do despotismo esclarecido. A filosofia do Direito Natural foi um instrumento poderoso que levou à reforma da Universidade de Coimbra pelo marquês de Pombal em 1772, contribuindo, assim, para a substituição da orientação escolástica predominante da época.

As transformações que tiveram lugar no campo do Direito Natural desde o século XVII contribuíram claramente para a definição gradual dos objetivos econômicos e políticos e para o oferecimento de instrumentos conceituais e metodológicos para o desenvolvimento do campo da economia política. Nesse contexto, a relação entre autointeresse e felicidade pública, concebida como uma relação de harmonia e equilíbrio, destaca-se como particularmente relevante, pois também se articula com a tradição cameralista do pensamento econômico. Na verdade, a própria noção de polícia (associada aqui com a ordem interna estabelecida pela ação do Estado, com base na produção da felicidade do bem comum e público) teve um papel importante como ponto de convergência dos diferentes discursos que levaram ao surgimento da economia política como um tipo de ciência do legislador, fornecendo, portanto, os meios necessários para promover a reforma política e as mudanças econômicas.

As ideias econômicas que formaram a base intelectual da ação governativa de Pombal podem ser descritas como uma espécie de combinação do cânone mercantilista (mais especificamente um determinado tipo de colbertismo) com uma atenção às matérias de polícia (que em Portugal significou o que podemos nomear como uma combinação de doutrinas de base cameralistas com a compreensão da polícia que prevalecia naquela época na literatura política francesa de absolutismo ilustrado). Assim, a polícia foi vista como uma referência a um conjunto de procedimentos destinados a assegurar a autoridade pública e a fortalecer o poder do Estado, ou, na terminologia utilizada por Michel Foucault, "o conjunto de meios (leis e regulamentos) através dos quais seria viável fazer crescer as forças do Estado, mantendo a boa ordem do Estado". ${ }^{20}$

Em síntese, a importância que essas matérias de polícia tiveram na estruturação do Estado português e em suas políticas reformistas no período é um

${ }^{20}$ Michel Foucault, Sécurité, territoire, population. Cours au Collège de France (1977-1978), Paris, Seuil-Gallimard, 2004, p. 321. 
claro sinal de que regalismo político e despotismo esclarecido não poderiam mais se basear exclusivamente no receituário tradicional do mercantilismo, havendo, portanto, a abertura a outras influências, nomeadamente ao cameralismo e às ciências da administração do Estado.

\section{Dom Rodrigo, economia política e política colonial ilustrada}

Como foi explicado na seção anterior, um dos maiores méritos das políticas de Pombal sobre o Brasil era de que elas permitiram uma reavaliação da adequação das instituições econômicas coloniais às necessidades tanto da administração central quanto da local. As medidas apresentadas revelam que houve um estímulo global às atividades econômicas no Brasil, especialmente àquelas em que o papel da colônia era fundamental para o equilíbrio da exportação e do comércio de reexportação em Portugal. No entanto, essas medidas também implicaram uma nova consciência da eficácia do regime tradicional de "pacto colonial", baseado no comércio exclusivo e nas práticas de monopólio concedidas pelo Estado e operadas por companhias de comércio com privilégios.

De 1790 em diante, especialmente quando Rodrigo de Sousa Coutinho tornou-se ministro da Marinha e Ultramar em 1796, um novo processo de reforma econômica e financeira foi lançado, com efeitos claros sobre a condução dos assuntos coloniais. Os objetivos e o âmbito dessas reformas mantiveram vivo o espírito do "pacto colonial", em perspectiva em boa medida análoga à reforçada por Pombal. Os principais problemas a cobrarem respostas no momento eram a necessidade de aumentar as receitas do Estado, o aumento da produção de mercadorias coloniais para reexportação, a expansão da estrutura de manufaturas na metrópole e a redução do contrabando no comércio colonial. A plena realização desses objetivos representava um sério desafio para as práticas existentes da administração colonial.

A prosperidade comercial vivenciada pelo império português no final do século XVIII deu-se em grande parte devido ao papel desempenhado pelo Brasil, não apenas como fornecedor de matérias-primas e gêneros alimentícios para os quais havia uma demanda crescente nos mercados europeus (em especial de açúcar e algodão) e, portanto, em associação direta com um intenso comércio de reexportação, mas, também, como consumidor de produtos fabricados na 
metrópole, assim como vinho e trabalho escravo das colônias africanas. ${ }^{21}$ Portanto, era natural que o ministro ilustrado, Rodrigo de Sousa Coutinho, estivesse sempre a manter uma estreita vigilância sobre a administração política e econômica do Brasil, ciente da importância crucial que a economia brasileira e o comércio colonial tinham para manter o equilíbrio econômico dentro do reino como um todo. No contexto mais amplo do equilíbrio de poder entre as nações europeias, a própria existência e a manutenção dos territórios coloniais eram um importante fator de diferenciação e uma condição fundamental para assegurar a supremacia econômica.

Coutinho não rompe com o modelo mercantilista tradicional sobre o papel das colônias nos impérios europeus. Apoiado por uma doutrina bem elaborada sobre a unidade política do território português no estrangeiro, ele estava, porém, pronto a admitir, uma vez que os "domínios de Sua Majestade na Europa não formam senão a capital e o centro das suas vastas possessões", 22 que a cada uma das províncias da monarquia, espalhadas por diferentes continentes, deveriam ser dados identidade e status. Isso era particularmente verdade para o caso do Brasil no século XVIII, uma vez que se fazia autoevidente sua importância econômica para o império. Já quanto à unidade econômica do império, Coutinho acreditava que as condições anteriores do pacto colonial não deveriam ser contestadas, porque "as relações de cada domínio devem em recíproca vantagem ser mais ativas e mais animadas com a metrópole do que entre si, pois que só assim a união e a prosperidade poderão elevar-se ao maior auge". ${ }^{23}$

\footnotetext{
${ }^{21} \mathrm{O}$ tópico vem merecendo análises tanto da historiografia brasileira como da portuguesa. Para os argumentos centrais da discussão, é imprescindível a referência a: Fernando Antônio Novais, Portugal e Brasil na crise do antigo sistema colonial (1777-1808), São Paulo, Hucitec, 1979; José Jobson de Andrade Arruda, O Brasil no comércio colonial, São Paulo, Hucitec, 1980; Valentim Alexandre, Os sentidos do império. Questão nacional e questão colonial na crise do Antigo Regime português, Porto, Edições Afrontamento, 1993; e Jorge M. Pedreira, Estrutura industrial e mercado colonial. Portugal e Brasil 1780-1830, Lisboa, Difel, 1994. Para um sumário crítico da discussão, veja também: José Luís Cardoso, "Free trade, political economy and the birth of a new economic nation: Brazil, 1808-1810", Revista de Historia Económica, Journal of Iberian and Latin American Economic History, n. 27, p. 2, 2009.

${ }^{22}$ Rodrigo de Sousa Coutinho, "Memória sobre o melhoramento dos domínios de Sua Majestade na América”. In: Textos políticos, económicos e financeiros (1783-1811), Lisboa, Banco de Portugal, v. I e II (organizados por Andrée Diniz Silva), 1993 [1797], p. 48.

${ }^{23}$ Ibidem, p. 49.
} 
No entanto, a confiança nesses princípios não o impediu de apresentar um programa equilibrado de reformas que incluía a redução da carga fiscal e que foi associado a uma vasta gama de atividades econômicas em curso no Brasil. Coutinho estava ansioso para aceitar certo grau de autonomia econômica das colônias, em particular pelo fato de que tinha ideia clara de que a negação a essa prerrogativa poderia inflamar os movimentos por independência. Como leitor do abbé Raynal e de outros autores iluministas que apresentaram reflexões críticas sobre a natureza do comércio colonial e a necessidade de sua reforma, Coutinho sabia que o velho "pacto colonial", o sistema baseado em contratos negociados e privilégios exclusivos, podia ainda ser sustentado, mas não poderia ser mantido vivo para sempre. Ele estava particularmente preocupado com a lógica do regime fiscal e certas políticas que se iniciaram essencialmente pela voracidade em relação às riquezas coloniais. Como leitor de Adam Smith, ele também estava bem informado sobre os sólidos princípios que os governos devem seguir no domínio da política fiscal, nomeadamente no que diz respeito às regras universais de segurança e conveniência que não deveriam estar em desacordo com as necessidades e anseios daqueles que pagavam tributos. ${ }^{24}$

Entre as reformas fiscais que Coutinho tentou implementar durante o seu mandato como ministro da Marinha e do Ultramar, entre 1796 e 1800, devem-se mencionar a redução à metade do imposto sobre mineração de ouro e uma redução geral (ou até mesmo a isenção total) de direitos de importação das mercadorias que entram nos portos brasileiros a partir de Portugal continental, nomeadamente vinho, azeite, ferro e produtos manufaturados para o consumo corrente. Também estava ele particularmente atento à necessidade de melhorar o sistema tributário e as técnicas contábeis utilizadas na gestão das finanças públicas.

Algumas das propostas apresentadas pelo ministro não foram implementadas com sucesso, embora seus princípios orientadores estivessem em sintonia com uma preocupação básica para prover ao Brasil uma estrutura de moderni-

\footnotetext{
${ }^{24}$ Para uma discussão geral das questões coloniais no pensamento de Adam Smith e na economia política ilustrada, veja: Bernard Semmel, The rise of free trade imperialism. Classical political economy, the empire of free trade and imperialism, 1750-1850, Cambridge, Cambridge University Press, 1970; D. Stevens, "Adam Smith and the colonial disturbance". In: Andrew Skinner and Thomas Wilson (orgs.), Essays on Adam Smith, Oxford, Clarendon Press, 1975; Donald Winch, Classical political economy and colonies, Londres, LSE, 1965. Reconhecemos, não sem pena, que o tema vem despertando interesse muito limitado dos historiadores do pensamento econômico nos últimos anos.
} 
zação econômica e financeira que estivesse em sintonia com as novas necessidades do império como um todo. No entanto, é bastante claro que a concretização dos objetivos de inovação e modernização implicou também a adoção de uma série de medidas que poderiam pôr em risco alguns dos privilégios básicos de um regime colonial do tipo mercantilista. Tal foi o caso com as propostas para a supressão dos contratos de monopólio sobre a pesca da baleia e sal e para a redução ou eliminação de tarifas sobre produtos metropolitanos em portos brasileiros. As instruções dadas aos governadores das províncias no Brasil também incluíram propostas idênticas para a abolição dos privilégios criados por contratos de exclusividade, com o argumento básico de que essa seria uma das principais formas de aumentar as receitas fiscais da coroa. O sistema de rendas de monopólio gerado por contratos de exclusividade foi rotulado por Coutinho de "um criminoso método". ${ }^{25}$ As restrições impostas à circulação de produtos no território brasileiro foram consideradas como produzindo "ordinariamente todo o mal, sem fazerem bem algum, quando pelo contrário a inteira e livre circulação de todos os artigos, e a segurança de um mercado, onde os preços só dependem da concorrência são os melhores meios de procurar uma segura abundância”. ${ }^{26}$ Foi precisamente no que diz respeito a essas questões que as ações Sousa Coutinho revelaram seu forte compromisso com a utilização de alguns dos argumentos iluministas fornecidos pelo sistema de economia política de Smith.

Uma das principais preocupações que tomaram forma ao longo da administração colonial ilustrada de Coutinho foi o apoio dado a um melhor conhecimento do território brasileiro e de seus recursos naturais. A organização das viagens filosóficas, a recolha de dados estatísticos, a descrição das condições de vida e os novos planos para a alocação de recursos econômicos foram todos assuntos que ganharam importância crescente para a concepção da política colonial, oferecendo uma clara evidência da relação de confiança colocada no conhecimento

\footnotetext{
${ }^{25}$ Arquivo Nacional do Rio de Janeiro, Ofícios e correspondência para os vice-reis e governadores das capitanias do Brasil (1796-1803), "Vice-reinado", Caixa 748, 10 de setembro de 1799. Sobre o conteúdo dessa correspondência e sobre o significado das reformas econômicas conduzidas por Sousa Coutinho, veja: José Luís Cardoso, "Nas malhas do império: a economia política e a política colonial de D. Rodrigo de Sousa Coutinho". In: José Luís Cardoso (org.), A economia política e os dilemas do império luso-brasileiro (1790-1822), Lisboa, Comissão Nacional para as Comemorações dos Descobrimentos Portugueses, 2001.
}

${ }^{26}$ Arquivo Nacional do Rio de Janeiro, "Vice-reinado", Caixa 744, 1ํ de outubro de 1799. 
científico como uma base sólida para a tomada de decisão política. Foi com esse objetivo em mente que Coutinho estabeleceu a Casa Literária do Arco do Cego, destinada à publicação de livros sobre temas científicos, como: agronomia, botânica, química, mineralogia, aplicados a uma melhor utilização e mais eficiente alocação econômica dos recursos naturais recursos no Brasil. A Casa Literária acabou por se constituir em uma rede eficiente de estudantes brasileiros e funcionários que residiam temporariamente no continente, mas que continuavam posteriormente ligados à instituição como seus correspondentes, permanentemente atentos ao imenso potencial de recursos brasileiros. Um sistema informal de bolsas de estudo tomava forma aí, o que permitia inclusive o pagamento de traduções, cabendo a Coutinho a gestão cuidadosa de toda essa rede de letrados. Ele também apoiou a Sociedade Real Marítima, Militar e Geográfica, à qual cabia a tarefa fundamental de produção de instrumentos cartográficos para a descrição do território brasileiro. Contudo, os estatutos dessa sociedade também indicavam o propósito de incentivar e complementar o conhecimento ilustrado como um meio "para poder elevar os meus domínios ao melhor estado de cultura, e promover as comunicações interiores, assim como favorecer o estabelecimento de manufaturas, que se naturalizem facilmente, achando uma situação territorial que mais lhes convenha”. ${ }^{27}$ Por conseguinte, é evidente que a política de melhoramentos posta em ação por Coutinho, inspirada em níveis diferentes pela linguagem da economia política, contribuiu de maneira substancial para mudanças na vida colonial.

As reformas empreendidas tanto por Pombal quanto por Coutinho durante a segunda metade do século XVIII revelam que a questão da administração colonial era um elemento-chave na organização econômica e financeira geral do reino. A aceitação de novas diretrizes para a política colonial estava sujeita à intermediação de interesses diferentes associados com a importância social e econômica, bem como ao poder das elites locais e nacionais no controle dos circuitos de produção e do comércio colonial. No entanto, o reconhecimento de princípios iluminados do governo era um processo mais amplo, capaz efetivamente de

\footnotetext{
${ }^{27}$ Alvará de criação da Sociedade Real Marítima, Militar e Geográfica, citado em José Luís Cardoso, "Nas malhas do império: a economia política e a política colonial de D. Rodrigo de Sousa Coutinho”. In: José Luís Cardoso (org.), A economia política e os dilemas do império luso-brasileiro (1790-1822), Lisboa, Comissão Nacional para as Comemorações dos Descobrimentos Portugueses, 2001, p. 91.
} 
demonstrar os atributos de um legislador sábio. Nesse sentido, as reformas que foram implementadas constituíram uma oportunidade para os administradores coloniais aceitarem as alterações que acabariam por levar a uma melhor alocação dos recursos econômicos disponíveis e, consequentemente, a um processo mais eficiente de criação de riqueza. A promoção de expedições científicas em todo o território brasileiro, mencionadas anteriormente, constitui um bom exemplo do papel atribuído à ciência e à razão esclarecida, a fim de obter um melhor conhecimento das reais capacidades econômicas da colônia. Ao mesmo tempo, essas expedições servem como uma evidência clara do processo de modernização e de mudança que se vislumbrava para o Brasil.

As mudanças que ocorreram na administração econômica do Brasil, particularmente aquelas relacionadas com a ação política de Coutinho no final do século XVIII, contribuíram, sem dúvida, para a disseminação de um novo tipo de discurso econômico que não podia mais aceitar o esquadro geral dos princípios da tradição mercantilista do velho "pacto colonial". No entanto, o grande momento que estabeleceu as condições políticas e econômicas favoráveis para a disseminação da nova ciência da economia política foi a transferência do rei e de sua corte ao Brasil em 1808, como resultado das guerras napoleônicas na Europa, uma vez que a partir daí já não haveria mais possibilidades de se reeditar aquele tipo de ambição. A abertura dos portos brasileiros ao comércio inglês foi a primeira medida política decidida pelo rei quando ele chegou à Bahia em janeiro de 1808. Não poderia ter havido melhor ato simbólico para indicar o começo do fim do regime colonial baseado no privilégio, no monopólio e na exclusividade, podendo a partir daí, como resultado disso, a nova linguagem do liberalismo econômico e da ideologia do laissez-faire dar facilmente passos seguros no território brasileiro. $^{28}$

${ }^{28}$ Cf. José Luís Cardoso, "Free trade, political economy and the birth of a new economic nation: Brazil, 1808-1810", Revista de Historia Económica, Journal of Iberian and Latin American Economic History, n. 27, p. 2, 2009. 


\section{Conclusão}

Em boa medida, a abertura às ideias políticas e econômicas que estavam para ser discutidas em diferentes cantos da Europa ao longo da segunda metade do século XVIII deve ser considerada como um fator-chave na execução de reformas coloniais no mundo português. As ideias ilustradas mostraram-se particularmente úteis na luta contra o controle estatal excessivo de atividades econômicas em geral e, simultaneamente, serviram como um apelo ao reforço do papel dos agentes econômicos privados. Nesse contexto, ênfase especial deve ser dada à maneira pela qual os reformadores portugueses interpretaram e aplicaram noções como as de "melhoramentos", "bem comum" e "felicidade pública", que eram conceitos então em voga nas literaturas econômica e política europeia e que aparecem com frequência nas obras de autores fisiocratas franceses, cameralistas alemães ou, posteriormente, nas obras de Adam Smith, no esquadro do Iluminismo escocês, com seu moderno sistema de economia política.

Essa nova abordagem da reforma política não enfraquece a mensagem apresentada pelas doutrinas regalistas, ou seja, o apelo a um reforço certo da intervenção estatal. No entanto, esse reforço não deve ser visto como negação do papel importante desempenhado pelos agentes individuais na vida econômica, mas, sim, como uma maneira de enfatizar a oposição ao sistema de privilégios concedidos pela Igreja e ordens religiosas, que foram consideradas como tendo efeitos negativos sobre a própria organização econômica e social. O programa de reformas implementadas em Portugal pelo marquês de Pombal, bem como os processos de tomada de decisões políticas associadas a isso, representou a introdução de um novo tipo de relação entre o Estado e a Igreja no qual era clara a vantagem do primeiro. $\mathrm{Na}$ verdade, a consequência imediata dessa nova compreensão do alcance do poder civil foi a diminuição da influência da Igreja sobre os domínios público e social e a redução substancial dos seus privilégios e imunidades.

A fusão desses dois discursos doutrinários (regalismo político e economia política) é a chave para a compreensão da natureza das reformas que, tanto no Brasil como na Europa, foram propostas e fomentadas por autores portugueses, visando à felicidade pública e à prosperidade econômica. É nesse contexto que a economia política surge como um tipo de ciência do legislador, o que vem a ser um poderoso instrumento para promover e dirigir um programa coerente de melhoramentos sociais que incluía especial preocupação com as questões coloniais. Essa interpretação geral não se opõe à permanência e à continuidade, ao longo do período em estudo, das decisões políticas inspiradas de forma mais ampla nos princípios mercantilistas. Há, no entanto, o espaço para essa dinâmica de recomposições que, ante a presença de diferentes matrizes de ideias, empurra o desenvolvimento de novas reformas econômicas e políticas. 